\title{
Analysis of Mental Health Indicators of Refugees in Supporting Cultural Environments in European Countries
}

\section{Zanganeh S*}

Faculty of Education, Queensland University of Technology, Australia

\begin{abstract}
The purpose of this study is analysis of mental indicators of SCL-90 in Asian refugees (Syria, Iraq, Afghanistan and Iran) in supporting cultural environment in European countries. The results of compulsory immigration research show that there is a strong correlation between the high rates of mental indicators among immigrant populations. The samples of the study have been immigrated in 2015. This study is descriptive-comparative. Sample of study include 124 refugee women and men that have the card (legal immigrants under the protection of the united nations). The SCL-90 questionnaire was distributed among them and the interview was conducted with a number of available sample members in order to clarifying the dimensions of their personality. Data were analyzed by spss22. The findings of this study indicate that there is a significant difference between refugee women and men in terms of somatization, psychosis and interpersonal sensitivity that in somatization and Interpersonal sensitivity women had a higher average than men and in psychosis men showed higher average than women. According to the results of the research, we can say women are more susceptible to mental problems than men. So therapeutic plans and prevention of mental disorders should be addressed to the women of this community.
\end{abstract}

Keywords: Mental indicators; Refugees; Men; Supporting cultural environments; European Countries

\section{Introduction}

Immigration has become one of the most complex problems of our time in the last century. Immigration has many reasons, including poverty, unemployment, disease, war and famine, and the factors which force people to emigrate [1]. Immigration is a form of geographic mobility or a place of population which takes place between two geographic units. Also, immigration is defined as the individual or collective displacement of humans with the decision to change the place of residence and work in the form of permanently or for a long time [2]. The concept of foreign migrant refers to someone who changes the country of residence. One of the concepts associated with immigration is asylum. A refugee is someone who has been forced to flee his or her country because of persecution, war, or violence [3]. A refugee has a well-founded fear of persecution for reasons of race, religion, nationality, political opinion or membership in a particular social group [4].

There are currently over 60 million refugees or internally displaced people across the globe. in 2015, the European Commission presented its 'European Agenda on Migration', which outlines the immediate measures and medium to long term needs in order to respond to and better manage the refugee crisis, not only in the EU but also in external relations as it is a global phenomenon [5].

Separation from family and community, not being accepted in the host country, being elderly or adolescent, not familiar with the language of the host country and lack of socioeconomic status, are factors affecting the mental health of immigrants and refugees. Immigration affects on the culture of countries [6]. They may accept the features of the larger and more advanced society, but they will not concurrent with it. In other words, their specific cultural features do not completely disappear [7]. When the change is acute and their adaptive mechanisms and social protections are not remedied. It may cause a lot of stress. Studies on immigrant and refugee populations have reported high prevalence of psychiatric disorders among them. Providing mental health for migrants and refugees requires knowledge of their mental health problems [8]. Their mental health status can help in the field of public health planning in the primary prevention for psychological health needs of immigrants and refugees. Cultural support environments are an independent, non-governmental, nonpolitical, and nonprofit organization that provides services for the growth, survival and high-quality care of refugees [9].

Based on mentioned points, this question is posed:

What is the status of refugees in a mental state? And is there a difference between refugees women and men in the SCL-90 mental indicators?

\section{A Look at Immigration to Europe}

The arrival of over one million migrants and refugees in Europe in 2015 has created a major crisis. European countries still have difficulty coping with this widespread wave of immigration and they are in conflict with the best way to accept and settle [10]. All people who arrive in Europe do not apply for asylum but many of them become refugees. In 2015, Germany received the highest number of asylum applications with more than 476,000 people. But a lot more of this figure has arrived in Germany. Officials say the German immigrant reception and registration system has counted a total of more than a million newcomers to the country. After Germany, in terms of applying for asylum, Hungary is ranked second. However, many have applied for asylum, the number of people whose applications have been approved is far less. In 2015, EU countries have applied for asylum to more than 292,000 refugees while during the same year, more than a million refugees have applied for asylum (Figure 1).

*Corresponding author: Zanganeh S, Higher Degree Researcher, Faculty of Education, Queensland University of Technology, Australia, Tel: +61 731383947 ; E-mail: zanganehnezhad.solmaz@hdr.qut.edu.au

Received July 02, 2018; Accepted July 12, 2018; Published July 20, 2018

Citation: Zanganeh S (2018) Analysis of Mental Health Indicators of Refugees in Supporting Cultural Environments in European Countries. J Ment Disord Treat 4 163. doi:10.4172/2471-271X.1000163

Copyright: (c) 2018 Zanganeh S. This is an open-access article distributed under the terms of the Creative Commons Attribution License, which permits unrestricted use, distribution, and reproduction in any medium, provided the original author and source are credited. 


\section{Accepted total refugees in each country}

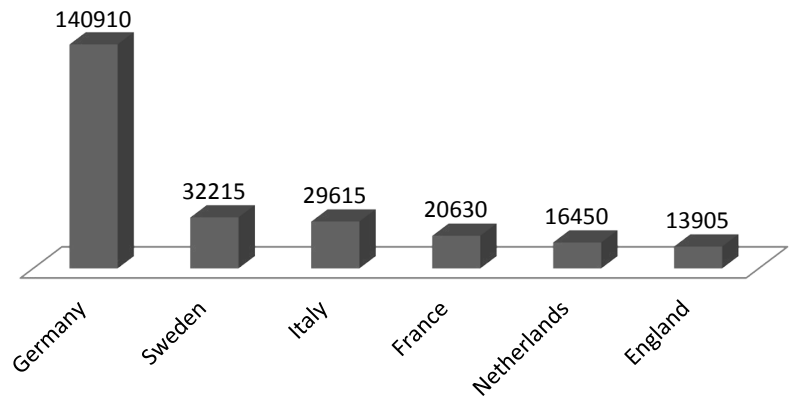

Figure 1: Accepted total refugees.

\section{Mental Health}

The health of a community is measured based on the health indicators of that community and their health is measured according to the trend of changes in these indicators over time. Indicators are variables that represent existing conditions and can be used to measure changes. Mental health index is defined as a measure of mental health status; this index is a variable that is linked to mental health and indicates a priority or a problem in this area [11]. The evaluation of mental health indicators is a very important necessity in evaluating the mental health status for mental health professionals and planners, to understand the important health priorities of the community and implement the provided programs in a desirable manner. In order to be useful indicators for monitoring the health and performance of the health system, should be used clear criteria to select and define health indicators [12]. Selection of criteria should be presented based on an agreement on what is measured and for the purpose of the measurement with a clear conceptual framework [13]. The conceptual framework should define the proper dimensions and sub-dimensions which are essential for describing the health of the community and the systemic performance of health care [14]. A conceptual framework of the health index can be made selection and meaningful interpretation of health indicators. By presenting the conceptual framework of mental health indicators can create a coherent set of mental health indicators [15]. Therefore, the present study aimed at examining the dimensions of the conceptual framework of mental health indicators.

\section{Mental health of refugees}

Increasing the number of refugees in recent years is unprecedented in the modern world. Currently, the responsibility for protecting mental health for refugees is by a network of agencies, including the UNHCR and WHO, government and nonprofit organizations, mental health and specialist refugee services, and voluntary organizations [16]. Across the world, refugees generally have less mental and physical health than the local population in which they resettle. In countries that are experiencing political instability and economic deprivation during the war or over the years, health care is generally low and living conditions are also intensifying and Causing migration and harm to health [17]. Identifying and appropriate treatment of mental health problems among new refugees and refugees in primary care, it is a challenge because of differences in language and culture and due to stressors associated with immigration and resettlement [18]. The prevalence of certain types of mental health problems affected by the nature of the immigration experience is in terms of anomalies which is experienced before, during and after resettlement. Specific challenges in migrants' mental health include communication problems due to differences in language and culture [19]. These issues can be addressed through specific studies, the use of trained translators and cultural agents, meetings with families, and consultation with social organizations. However, the unpredictable fact is that most refugees with mental health problems will never receive the right service. Therefore, the mental health of refugees should include the inclusion of this population in comprehensive programs of mental health care, an issue which is now widely recognized and approved in training and policy programs $[20,21]$.

\section{Method}

\section{Society, sample and sampling method}

The statistical population included persian language refugees in supporting cultural environment in european countries. The sample of this study included 141. Refugees and obtained through random sampling available using the Morgan table. Of these, about 17 were eliminated because of the incompleteness of the questionnaires. Of these, 45 were women and 79 were men.

\section{Research tool}

The used tool in this research is SCL-90 questionnaire. This questionnaire was introduced for the first time In 1973 by Derogatis et al. based on clinical experiences and psychometric analyzes (Derogatis, et al.). Since then, this questionnaire has been used in many studies. This questionnaire is a list of self-reported psychological symptoms and contains 90 questions which were created by clinical psychological research and its design was to reflect the pattern of mental symptoms of physical and mental patients. The questionnaire consists of 90 items and examines 9 dimensions of mental disorders, which include: somatization, obsessive-compulsive, interpersonal sensitivity, depression, anxiety, hostility, phobic anxiety, paranoid ideation, psychosis. On this scale, there are seven additional substances

And they are not classified in any of the numbers and are referred to as "Others". Each of the test questions consists of 5 degrees of discomfort which is from the zero score (no) up to four (severely).

\section{Validity of the questionnaire}

Derogatis reported that in order to calculate the internal consistency of the questionnaire, which was conducted on 219 volunteers in the United States (to measure the credibility of the questionnaire), have been used the alpha coefficients and Richardson 20 and the results of the coefficients obtained for 9 dimension were quite satisfactory. Testretest reliability which measures the stability of the questionnaire over time Calculated on 16 psychologically compatible patients after a week after the initial evaluation. The results showed that in most cases there were high correlation coefficients.

\section{Method of implementation}

At first, theoretical studies were conducted on the variables of the research. A sample was selected from refugees in Europe. After the implementation of the necessary coordination with the foreign migration board and obtaining the necessary permission, questionnaires were distributed among the refugees. After completing the questionnaires, the data were analyzed in line with the purpose of the research.

\section{Findings}

The demographic status of the sample is presented in the following 
(Table 1). As seen in the table above, the majority of the sample is men. In terms of nationality, the Syrians (27.4\%) have the highest number of asylum seekers. Throughout the history of Syria, there was no real stability to return to those who have left it. This area remains in political, military and economic crises. Given that before the syrian war, there have been many clashes and disruptions in european countries, but we did not witness the return of syrian refugees to their secure country. Probabilities are coming in this direction which with ending of the clashes and wars in syria, refugees will not return to this country. Even if syria becomes a stable country and has economic growth. After Syria, Afghanistan (25.8\%) has second ranks in the percentage of refugee population and then Iran $(24.2 \%)$ and Iraq $(22.6 \%)$ are ranked second and third. In terms of gender, men $(63.7 \%)$ accounted for a greater percentage of the population. Moreover, in the sample of research, couples $(62 \%)$ are more likely to asylum. The majority of the population in the present study is between the ages of 15 and 30 years (40\%) and people over 45 years of age (8\%) show the lowest percentage of the population.

In order to compare the psychological aspects of SCL-90 in refugee women and men were used multivariate analysis of variability and normality default. The results are presented in Table 2.

The results of Table 1 show that the variables in the two gender groups have normal distribution.
The results of comparing the psychological aspects of refugee women and men are presented in the following table using Multivariate Analysis.

As can be seen, the results of Table 2 show that there is a significant difference between women and men in terms of somatization, psychosis and interpersonal sensitivity that women had a higher average than men in somatization and interpersonal sensitivity and in psychosis, men showed a higher mean than women. In other dimensions of depression, anxiety, phobic anxiety, obsessive-compulsive, paranoid ideation and hostility were not significantly different among the two sexes.

\section{Discussion and Conclusion}

At present, the number of refugees who migrated to European countries in recent years and left their country is not considered and even their return to their own country was not given importance after the end of the war. Because refugees have become familiar with other cultures and western culture is being shaped on them. They seek to build their future away from their country.

According to the statistical data obtained through this research and scientific research it can be concluded that women are more prone to psychological problems than men. According to the interviews, it is said that the group is constantly confused between the memories and

\begin{tabular}{|c|c|c|c|c|c|c|c|c|c|c|c|}
\hline \multicolumn{4}{|c|}{ Gender } & \multicolumn{8}{|c|}{ Nationality } \\
\hline \multicolumn{2}{|c|}{ Women } & \multicolumn{2}{|c|}{ Men } & \multicolumn{2}{|c|}{ Afghanistan } & \multicolumn{2}{|c|}{ Iraq } & \multicolumn{2}{|c|}{ Syria } & \multicolumn{2}{|c|}{ Iran } \\
\hline Number & $\begin{array}{c}\text { Frequency } \\
\text { Percentage } \\
(\%)\end{array}$ & Number & $\begin{array}{c}\text { Frequency } \\
\text { Percentage } \\
(\%)\end{array}$ & Number & $\begin{array}{c}\text { Frequency } \\
\text { Percentage } \\
(\%)\end{array}$ & Number & $\begin{array}{c}\text { Frequency } \\
\text { Percentage } \\
(\%)\end{array}$ & Number & $\begin{array}{c}\text { Frequency } \\
\text { Percentage } \\
(\%)\end{array}$ & Number & $\begin{array}{c}\text { Frequency } \\
\text { Percentage } \\
(\%)\end{array}$ \\
\hline 45 & 36.3 & 79 & 63.7 & 32 & 25.8 & 28 & 22.6 & 34 & 27.4 & 30 & 24.2 \\
\hline \multicolumn{4}{|c|}{124} & \multicolumn{8}{|c|}{124} \\
\hline \multicolumn{4}{|c|}{ Marital status } & \multicolumn{8}{|c|}{ Age } \\
\hline \multicolumn{2}{|c|}{ Single } & \multicolumn{2}{|c|}{ Married } & \multicolumn{2}{|c|}{$1-15$} & \multicolumn{2}{|c|}{$15-30$} & \multicolumn{2}{|c|}{$30-45$} & \multicolumn{2}{|c|}{$>45$} \\
\hline Number & $\begin{array}{c}\text { Frequency } \\
\text { Percentage } \\
(\%)\end{array}$ & Number & $\begin{array}{c}\text { Frequency } \\
\text { Percentage } \\
(\%)\end{array}$ & Number & $\begin{array}{c}\text { Frequency } \\
\text { Percentage } \\
(\%)\end{array}$ & Number & $\begin{array}{c}\text { Frequency } \\
\text { Percentage } \\
(\%)\end{array}$ & Number & $\begin{array}{c}\text { Frequency } \\
\text { Percentage } \\
(\%)\end{array}$ & Number & $\begin{array}{c}\text { Frequency } \\
\text { Percentage } \\
(\%)\end{array}$ \\
\hline 47 & 38 & 53 & 62 & 36 & 29.2 & 40 & 32.2 & 38 & 30.6 & 10 & 8 \\
\hline \multicolumn{4}{|c|}{124} & \multicolumn{8}{|c|}{124} \\
\hline
\end{tabular}

Table 1: Demographic status of the sample.

\begin{tabular}{|c|c|c|c|c|c|c|c|}
\hline \multirow[t]{2}{*}{ Variable } & \multirow[t]{2}{*}{ Refugees } & \multicolumn{3}{|c|}{ Kolmogorov-Smirnov test } & \multicolumn{3}{|c|}{ Shapiro-Wilk test } \\
\hline & & Statistics & Df & Sig & Statistics & Df & Sig \\
\hline \multirow[t]{2}{*}{ Depression } & Women & 0.014 & 44 & 0.000 & 0.014 & 44 & 0.000 \\
\hline & Men & 0.019 & 78 & 0.000 & 0.011 & 78 & 0.000 \\
\hline \multirow[t]{2}{*}{ Somatization } & Women & 0.025 & 44 & 0.000 & 0.030 & 44 & 0.0005 \\
\hline & Men & 0.001 & 78 & 0.0001 & 0.019 & 78 & 0.000 \\
\hline \multirow[t]{2}{*}{ Psychosis } & Women & 0.055 & 44 & 0.000 & 0.020 & 44 & 0.000 \\
\hline & Men & 0.001 & 78 & 0.000 & 0.014 & 78 & 0.000 \\
\hline \multirow[t]{2}{*}{ Phobic Anxiety } & Women & 0.016 & 44 & 0.000 & 0.060 & 44 & 0.000 \\
\hline & Men & 0.002 & 78 & 0.0005 & 0.031 & 78 & 0.000 \\
\hline \multirow[t]{2}{*}{ Obsessive-Compulsive } & Women & 0.049 & 44 & 0.000 & 0.017 & 44 & 0.0001 \\
\hline & Men & 0.025 & 78 & 0.000 & 0.003 & 78 & 0.000 \\
\hline \multirow[t]{2}{*}{ Paranoid Ideation } & Women & 0.049 & 44 & 0.0001 & 0.002 & 44 & 0.000 \\
\hline & Men & 0.005 & 78 & 0.000 & 0.001 & 78 & 0.000 \\
\hline \multirow[t]{2}{*}{ Interpersonal sensitivity } & Women & 0.006 & 44 & 0.000 & 0.061 & 44 & 0.0001 \\
\hline & Men & 0.008 & 78 & 0.000 & 0.041 & 78 & 0.000 \\
\hline \multirow[t]{2}{*}{ Anxiety } & Women & 0.014 & 44 & 0.000 & 0.002 & 44 & 0.000 \\
\hline & Men & 0.011 & 78 & 0.0001 & 0.006 & 78 & 0.000 \\
\hline \multirow[t]{2}{*}{ Hostility } & Women & 0.036 & 44 & 0.000 & 0.059 & 44 & 0.000 \\
\hline & Men & 0.015 & 78 & 0.000 & 0.011 & 78 & 0.000 \\
\hline
\end{tabular}

Table 2: Being normal Test of distribute data in refugees women and men in European. 
past experiences of their disasters and their uncertain future, this is an indication of the symptoms of depression. As outlined in the fifth edition of DSM, Some disorders such as major depressive disorder and panic disorder appear at first with mostly physiological symptoms (DSM-5, APA, 2013). According to interviews, somatization such as headache and stomach pain and sometimes the back pain of this group declared the nervous agent by doctors and in just a few cases, the cause of headaches is high or low pressure. Therefore, it can be said that the depression of this group causes pain in the body and ultimately somatization. Along with this study, Cotton and Walker pointed out that although patients were considered with physical complaints, not medical diagnosis as worried healthy people, but many studies show that these patients have a high prevalence of undiagnosed anxiety and depression. This group in addition to lack of economic independence that puts them at the lowest economic level, are illiterate or illiterate, which itself is subject to environmental factors which is named in the fifth edition of DSM as the risk factor for this disorder" This disorder is more visible in those who have less education and lower socioeconomic status and those who recently have exposed to stressful life events" (DSM-5, APA, 2013). Also, according to interviews, it can be seen that refugee's women suffer from high stress and anxiety that is along with airfaya. In his study, he used the SCL-90 questionnaire on Arab immigrants, especially women and he concluded that this group had a high degree of stress, although the lack of mobility and also the lack of proper diet could be a reason for being stable such somatization in this group.

From the point of view psychosis men have the highest average. According to the interviews, it is possible to detect suspicion in men. Most of men are pessimistic about some of the promises and laws which are promised. They are suspicious especially for the improvement of their country and return which is offered to them for voluntary return. They think all these promises are explicitly false.

According to the results of this study, can be explained That the causes of psychological disorders in migrants in addition to the consequences of immigration from the country of origin can be pointed out the problems that immigrants face in the destination country Including racial discrimination, Cultural differences, social differences and inappropriate social encounters, people, political and economic constraints. Also, the impact of these problems on women is more than men. Therefore, it is recommended to familiarize with the psychological state of refugees, organizations involved in immigration and asylum put priority on the psychological issues of immigrants to get a fairer result in immigration laws.

The following can be considered in the context of the mental health problems of refugees:

Supporting of social integration through education, housing and employment; providing available services in order to facilitating access to care; coordinating various services in the health care system to reaching ensure the integration of physical and mental health care as well as appropriate care patterns; and training health care giver to ensure that they are focus on refugees, awareness of existing barriers to access to care and engagement with health services, and skills in overcoming language difficulties.

\section{References}

1. Nygaard M, Sonn C, Carlsson J (2017) Secondary psychotic features in refugees diagnosed with post-traumatic stress disorder: a retrospective cohort study. BMC Psychiatry.
2. Priebe S, Giacco D, El-Nagib R (2016) Public health aspects of mental health among migrants and refugees: a review of the evidence on mental health care for refugees, asylum seekers and irregular migrants in the WHO European region. Copenhagen: WHO Regional Office for Europe.

3. Beiser M (2009) Resettling refugees and safeguarding their mental health lessons learned from the Canadian Refugee Resettlement Project. Transcult Psychiatry 46: 539-583.

4. Verduin F, Smid GE, Wind TR (2014) In search of links between social capital, mental health and sociotherapy: a longitudinal study in Rwanda. Soc Sci Med 121: 1-9.

5. Policy Department for Structural and Cohesion Policies (2017) Directorategeneral for international policies, European parliament.

6. Noh S, Kaspar V, Wickrama KA (2007) Overt and subtle racial discrimination and mental health: preliminary findings for Korean immigrants. Am J Public Health 97: 1269-1274.

7. Lindencrona F, Ekblad S, Hauff E (2008) Mental health of recently resettled refugees from the Middle East in Sweden: the impact of pre-resettlement trauma, resettlement stress and capacity to handle stress. Soc Psychiatry Psychiatr Epidemiol 43: 121-131.

8. Slone M, Mann S (2016) Terrorism and armed conflict on young children: A systematic review. Child Psychiatry Hum Dev 47: 950-965.

9. Silove D, Austin P, Steel Z (2007) No refuge from terror: the impact of detention on the mental health of trauma-affected refugees seeking asylum in Australia. Transcult Psychiatry 44: 359-393.

10. United High Commissioner for Refugees (2016) Forced displacement 2015 Geneva: United High Commissioner for Refugees.

11. Betancourt TS, Chambers DA (2016) Optimizing an era of global mental health implementation science. JAMA Psychiatry 73: 99-100.

12. Kandula NR, Kersey M, Lurie N (2004) Assuring the health of immigrants: what the leading health indicators tell us. Annu Rev Public Health 25: 357-376.

13. First MB, Reed GM, Hyman SE, Saxena S (2015)The development of the ICD-11 clinical descriptions and diagnostic guidelines for mental and behavioural disorders. World Psychiatry 14: 82-90.

14. Norredam M, Garcia-Lopez A, Keiding N, Krasnik A (2009) Risk of menta disorders in refugees and native Danes: a register-based retrospective cohort study. Soc Psychiatry Psychiatr Epidemiol 44: 1023-1029.

15. Tay AK, Rees S, Chan J (2015) Examining the broader psychosocial effects of mass conflict on PTSD symptoms and functional impairment amongst West Papuan refugees resettled in Papua New Guinea (PNG). Soc Sci Med 132 70-78

16. World Health Organization (2015) United Nations High Commissioner for Refugees. mhGAP Humanitarian Intervention Guide (mhGAP-HIG): clinical management of mental, neurological and substance use conditions in humanitarian emergencies. Geneva: World Health Organization.

17. Sharma M, Fine SL, Brennan RT, Betancourt TS (2017) Coping and mental health outcomes among Sierra Leonean war-affected youth: results from a longitudinal study. Dev Psychopathol 29: 11-23.

18. Charlson FJ, Diminic S, Lund C, Degenhardt L, Whiteford HA (2014) Mental and substance use disorders in Sub-Saharan Africa: predictions of epidemiological changes and mental health workforce requirements for the next 40 years. PLoS One 9: 110-208.

19. Murray LK, Jordans M (2016) Rethinking the service delivery system of psychological nterventions in low and middle income countries. BMC Psychiatry 16: 234

20. Canetti D, Snider KL, Pedersen A, Hall BJ (2016) Threatened or threatening? How ideology shapes asylum seekers' immigration policy attitudes in Israel and Australia. J Refug Stud 29: 583-606.

21. United Nations Refugee Agency (2016) Global trends report: world at war Geneva: United Nations High Commissioner for Refugees. 